\title{
Physician Compensation Method Effects on Preventive Service Delivery
}

J Gen Intern Med 37(2):480-1 DOI: $10.1007 / \mathrm{s} 11606-020-06580-\mathrm{w}$

(c) Society of General Internal Medicine 2021

\section{INTRODUCTION}

Chronic disease is the leading cause of death, disability, and a leading driver of the $\$ 3.5$ trillion annual health care costs in the USA. ${ }^{1}$ Preventive care guidelines, such as those published by the United States Preventive Services Task Force (USPSTF), have been shown to be important in the maintenance, alleviation, and prevention of chronic disease. ${ }^{2}$ In addition, evidence has shown that preventive care plays a vital role in longevity and improved quality of life and in healthy individuals. ${ }^{3}$ However, studies have shown preventive service delivery rates by physicians are low, with physicians reporting lack of time, reimbursement structures, and financial considerations as barriers to service. ${ }^{4-6}$ The purpose of this study was to examine the association between physician compensation method and preventive service delivery rates. Additionally, this study examined the association between physician compensation and duration of office visit, as it has been reported in the literature as a barrier to preventive service delivery. ${ }^{4-6}$

\section{METHODS}

\section{Data}

This study examined office visits using pooled data from the 2011-2016 National Ambulatory Medical Care Survey (NAMCS), a nationally representative survey of office-based visits to physicians in the USA. Office visits were limited to those by adults age 18-64 in which physicians self-identified as the patients' primary care physician and listed the major reason for the visit as preventive care. Only visits to physicians compensated by salaried, productivity-based, or mix (mix of salary and share of billings or other measures of performance (e.g., your own billings, practice financial performance, quality measures, practice profiling)) compensation models were included in the study. All analyses used the survey procedures of Stata SE, version 16.0.

Received October 6, 2020

Accepted December 29, 2020

Published online January 22, 2021

\section{Measures}

For this study, the 101 preventive service recommendations published [as of April 2020] by the USPSTF were reviewed. The 101 recommendations were narrowed to 9 preventive services applicable to the majority of adults age 18-64 (Table 1). Only currently active recommended preventive services with a Task Force grade of "A" or "B" categorized as "screening" or "counseling" interventions were used for this study. Preventive services were further limited to those where at least 30 visits with those services to each of the three types of compensation methods were included in the sample, which is required to produce stable estimates, resulting in three preventive services being examined: blood pressure, cervical cancer screening, and obesity-related counseling.

\section{RESULTS}

The final sample consisted of 2575 office visits. Table 2 shows the weighted odds ratios of services provided by the physician compensation method. Visits by women had 2.36 times the odds of including cervical cancer screenings in salary-based visits, and 2.43 times the odds in mixed-compensation visits compared to productivity-based visits $(p<0.10)$. The odds of receiving a high blood pressure screening in mixedcompensation office visits was 2.42 times that of productivity-based office visits $(p<0.10)$, and 2.04 times that of salary-based office visits $(p<0.15)$. There were no statistically significant differences in the odds of providing obesityrelated counseling by compensation method.

Visit duration varied by type of physician compensation. Overall, the average visit duration across all visits was 22.8 min (95\% CI: 21.6-23.9). Salary-based physicians spent the most time, averaging $24.8 \mathrm{~min}$ (95\% CI: 22.8-26.8), followed by mixed compensation at $21.4 \mathrm{~min}(95 \% \mathrm{CI}$ : 20.1-22.7), and productivity-based physicians spent the least time, averaging $20.2 \mathrm{~min}$ (95\% CI: 18.4-22.1).

\section{DISCUSSION}

The study showed variance in the rates of preventive service delivery by physician compensation methods. This study found that for two of the three services examined, the odds of receiving preventive care was higher in salary and mixedcompensation models when compared to productivity-based 
Table 1 Sample Demographics (Unweighted)

\begin{tabular}{|c|c|c|c|c|}
\hline Service & All visits, $N \%$ & Salary, $n \%$ & Productivity, $n \%$ & Mixed, $n \%$ \\
\hline Patient visits ( $n$ raw) & 2575 & $1069[42 \%]$ & $577[22 \%]$ & $929[36 \%]$ \\
\hline Patient visits ( $n$ weighted) & $120,947,733$ & $56,561,241$ & $23,896,665$ & $40,489,827$ \\
\hline Age (years) & 44.3 & 44.1 & 44.2 & 44.7 \\
\hline \multicolumn{5}{|l|}{ Sex } \\
\hline Male & $937(36 \%)$ & $379(35 \%)$ & $235(41 \%)$ & $323(35 \%)$ \\
\hline Female & $1638(64 \%)$ & $690(65 \%)$ & $342(59 \%)$ & $606(65 \%)$ \\
\hline \multicolumn{5}{|l|}{ Race-Ethnicity } \\
\hline Non-Hispanic White & $1631(63 \%)$ & $698(65 \%)$ & $339(59 \%)$ & $594(64 \%)$ \\
\hline Non-Hispanic Black & $283(11 \%)$ & $133(12 \%)$ & $67(12 \%)$ & $83(9 \%)$ \\
\hline Non-Hispanic Other & $661(26 \%)$ & $238(22 \%)$ & $171(30 \%)$ & $252(27 \%)$ \\
\hline Hispanic & $191(7 \%)$ & $91(9 \%)$ & $32(6 \%)$ & $68(7 \%)$ \\
\hline \multicolumn{5}{|l|}{ Insurance type } \\
\hline Private & $1969(77 \%)$ & $824(77 \%)$ & $411(71 \%)$ & $734(79 \%)$ \\
\hline Medicaid & $299(12 \%)$ & $110(10 \%)$ & $73(13 \%)$ & $116(12 \%)$ \\
\hline Medicare & $128(5 \%)$ & $58(5 \%)$ & $31(5 \%)$ & $39(4 \%)$ \\
\hline Other & $190(7 \%)$ & $80(7 \%)$ & $65(11 \%)$ & $45(5 \%)$ \\
\hline Uninsured & $65(3 \%)$ & $28(3 \%)$ & $20(3 \%)$ & $17(2 \%)$ \\
\hline \multicolumn{5}{|l|}{ Physician specialty } \\
\hline General and Family Practice & $1132(44 \%)$ & $508(58 \%)$ & $226(39 \%)$ & $398(43 \%)$ \\
\hline Internal Medicine & $869(34 \%)$ & $395(37 \%)$ & $216(37 \%)$ & $258(28 \%)$ \\
\hline $\mathrm{OB} / \mathrm{GYN}$ & $377(15 \%)$ & $120(11 \%)$ & $71(12 \%)$ & $186(20 \%)$ \\
\hline Other & $197(8 \%)$ & $46(4 \%)$ & $64(11 \%)$ & $87(9 \%)$ \\
\hline
\end{tabular}

models, although results were not significant at the $p<0.05$ level. This was observed for high blood pressure screenings and for cervical cancer screenings. Mixed-compensation visits showed higher odds of high blood pressure screenings compared to salary-based visits. A possible explanation for differences in the likelihood of providing preventive services could be differences in visit duration by compensation method. Both salary-based physicians and mixed-compensation physicians averaged more time with patients during office visits compared to productivity-based physicians. A major limitation of this study was the sample size, which significantly limited statistical power and the ability to examine other preventive services. Additionally, this was a cross-sectional study; therefore, only associations could be assessed. Future studies are

Table 2 Odds of Receiving Services

\begin{tabular}{lllll}
\hline \hline Service & $\begin{array}{l}\text { Salary } \\
{[\mathbf{9 5 \%}} \\
\mathbf{C I}]\end{array}$ & $\begin{array}{l}\text { Productivity } \\
\text { [reference } \\
\mathbf{1 . 0}\end{array}$ & $\begin{array}{l}\text { Mixed } \\
\text { [95\% } \\
\mathbf{C I}]\end{array}$ & $\begin{array}{l}\text { a Salary: } \\
\text { Mixed }\end{array}$ \\
\hline High blood & 1.19 & - & $2.42^{\dagger}$ & $0.49^{\dagger \dagger}$ \\
pressure & {$[0.46$,} & & 70.84, & \\
& $3.05]$. & & $7.00]$ & \\
Cervical & $2.36^{\dagger \dagger}$ & - & $2.43^{\dagger \dagger}$ & 0.97 \\
cancer & {$[0.85$,} & & {$[0.95$,} & \\
& $6.51]$ & - & $6.22]$ & \\
Weight loss to & 0.94 & 1.16 & 0.81 \\
prevent & {$[0.43$,} & & {$[0.48$,} & \\
obesity-related & $2.05]$ & & $2.80]$ & \\
morbidity and & & & & \\
mortality & & & & \\
\hline
\end{tabular}

Note. Productivity visits are the reference group. Values represent odds of receiving each service in relation to productivity-based physicians ${ }^{a}$ Odds ratio comparing salary visits to mixed visits, with Salary as the reference

*The National Ambulatory Medical Care Survey (NAMCS) states for all estimates, other than estimates of proportion, at least 30 observations $\underset{t p<0.15}{\text { should be present }}$

$+0<0.10$

${ }^{t} p<0.10$ needed to understand the association of physician compensation with other types of preventive services. Physicians should be aware of the association between compensation and services provided, as it could be driving how they practice.

Cuneyt Ozkardes, $M S^{1}$

Jeffrey S. Harman, $\mathrm{Ph} \mathrm{D}^{1}$

${ }^{1}$ College of Medicine, Florida State University, Tallahassee, FL, USA

Corresponding Author: Cuneyt Ozkardes, MS; College of Medicine, Florida State University, Tallahassee, FL, USA (e-mail: co15@med.fsu.edu).

Compliance with Ethical Standards: The authors report no Conflict of Interest for this article.

\section{REFERENCES}

1. CDC - National Center for Chronic Disease Prevention and Health Promotion. (2019). About chronic disease. Available from: https://www. cdc.gov/chronicdisease/about/index.htm

2. Raghupathi W, Raghupathi, V. An empirical study of chronic diseases in the United States: A visual analytics approach. IJERPH. 2018; 15(3), E431.

3. Maciosek MV, Coffield AB, Flottemesch TJ, Edwards NM, Solberg LI. Greater use of preventive services in U.S. health care could save lives at little or no cost. Health Aff 2010; 29( 9), 1656-1660.

4. Yarnall KSH, Østbye T, Krause KM, Pollak KI, Gradison M, Michener JL. Family physicians as team leaders: "time" to share the care. Prev Chronic Dis 2009; 6(2), A59.

5. Borksy, A, Zhan, C, Miller, T, Ngo-Metzger Q, Bierman AS, Myers D. Few Americans receive all high-priority, appropriate clinical preventive services. Health Aff 2018; 37(6), 925-928.

6. Levine $\mathbf{S}$, Malone $\mathbf{E}$, Lekiachvili A, Briss $\mathbf{P}$. Health care industry insights: Why the use of preventive services is still low. Prev Chronic Dis 2019; 16(30), 1-6.

Publisher's Note: Springer Nature remains neutral with regard to jurisdictional claims in published maps and institutional affiliations. 